\title{
AEROMAGNETIC MAP OF THE PROVIDENCE QUADRANGLE, PROVIDENCE AND KENT COUNTIES, RHODE ISLAND
}

GEOPHYSICAL INVESTIGATIONS

MAP GP- 790

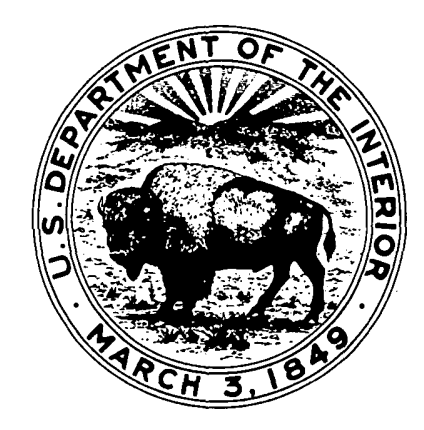

PUBLISHED BY THE U.S. GEOLOGICAL SURVEY 